\title{
Assessment of Evidence-Based Practice Knowledge, Utilization of Practice and Associated Factors on Nurses Working in the Adult Intensive Care Unit of Federal Public Hospital in Addis Ababa
}

\section{Zerihune Alene}

St Paul's Hospital Millennium Medical College

\section{Negat W/Hawariat}

St Paul's Hospital Millennium Medical College

\section{Helina Bogale}

St Paul's Hospital Millennium Medical College

Ayele Fikadu

SPHMMC: St Paul's Hospital Millennium Medical College

Abdata Workina ( $\square$ abdeta.15@gmail.com )

Jimma University College of Public Health and Medical Sciences https://orcid.org/0000-0002-68055011

\section{Research}

Keywords: Evidence based practice, knowledge, utilization, associated factors, and ICU

Posted Date: October 29th, 2021

DOl: https://doi.org/10.21203/rs.3.rs-966691/v1

License: (c) (1) This work is licensed under a Creative Commons Attribution 4.0 International License.

Read Full License 


\section{Abstract \\ Background}

Critical care nurses face several challenges in providing safe, evidence-based care for critical patients. Evidence-based practices are important to improve the overall quality of patient care, enhance nursing practice, and increase confidence in evidence-based decision-making. Thus, this study was intended to assess evidence-based practice knowledge and utilization of the practice on nurses working in the adult intensive care units.

\section{Methods}

Institutional based cross-sectional study was employed on 135 randomly selected nurses working in adult intensive care units of federal public hospitals in Addis Ababa, Ethiopia, from April 3 to December 21,2020 . Data were collected using a structured questionnaire through face-to-face interviews. Then, it was entered into Epi data version 4.4.2.1, and exported to SPSS version 25 for analysis. In the bivariate logistic regression analysis, predictors variables with $p<0.25$ were fitted to multivariate analysis. Then, the adjusted odds ratio with $95 \% \mathrm{Cl}$ was used to report the association at $\mathrm{P}<0.05$.

\section{Results}

Among the study participants, about $92(68.1 \%)$ and $115(85.2 \%)$ of them were found to have good knowledge and utilization of evidence-based practice, respectively. Predictors like difficulty to properly interpret research results (AOR=11.36; 95\% Cl: 1.86-69.39), and insufficient resources to implement changes in practice (AOR=4.44; $95 \% \mathrm{Cl}: 1.05-18.80)$ were associated with poor knowledge of evidencebased practice. Moreover, nurses who were not able to interpret research results, lack of nursing colleague support, and insufficient time were significantly associated with poor utilization $(P<0.05)$.

\section{Conclusion}

The knowledge and utilization of evidence-based practice among nurses was found to be high compared to the findings of former studies. Inability to properly interpret research results, lack of confidence, insufficient time, and lack of nursing colleague support were independently associated with poor knowledge and utilization of evidence-based practices among nurses working in adult ICU nurses.

\section{Introduction}

Evidence-based practice (EBP) is the conscientious, explicit, and judicious use of current best evidence in making decisions about the care of individual patients, and the integration of best research evidence with clinical expertise and patient practice to predict patient outcomes, improve care quality, and contain 
costs. ${ }^{1-4}$ The EBP process includes five elements: formulating an appropriate question, performing an efficient literature search, critically appraising the best available evidence, applying the best evidence to clinical practice, and assessing outcomes of care. ${ }^{5-7}$

In the 21-century, low implementation of EBP among nurses show substantial serious health problem and medical errors for patients in many places worldwide: In the United States, more than 800,000 Americans require invasive mechanical ventilation in the intensive care unit (ICU) each year, many of these patients do not receive care via evidence-based practices. About $65.5 \%$ of the nurses could not regularly implement EBP in treating patients. ${ }^{8}$ A study report conducted in East Africa, Ethiopia and Kenya shows that, $17.5 \%$ and $92 \%$ of nurses do not fully utilize research evidence when providing nursing care respectively. ${ }^{9,10}$ Due to the lack of implementation of evidence-based practice during patient care, about $20-25 \%$ of treatments may be unnecessary or even harmful. ${ }^{11}$

Research findings suggest that nurses perceived a lot of barriers or factors to implement evidence-based practice in the clinical setting such as lack of time, heavy workload, lack of knowledge about EBP, limited access to literature, computer skills, lack of training in information seeking and critical appraisal skills. ${ }^{12-}$ 15

Furthermore, in the intensive care unit, applying of evidence-based practice implementation can be challenging, also factors, such as dramatic changes in the health care system, increasing emphasis on quality of care, cost limitations, increasing patient and professional expectations, pressure for patient centered care and transparency in delivering clinical care increasingly push the health care industry towards the utilization of more scientific research globally. ${ }^{16-19}$ Therefore, the nursing profession as a practical discipline is expected to be accountable for integrating the best research evidence into the decision-making process with the aim of improving care. To achieve this goal, evidence-based practice (EBP) was introduced as an important initiative to health care system. ${ }^{15,20,21}$

Therefore, this study was aimed to identify a gap related to evidence-based practice knowledge, utilization of practice and associated factors on nurses working in the adult intensive care units.

\section{Methods And Materials}

\section{Study Design and Setting}

An institutional-based cross-sectional study design was conducted at selected federal public hospitals of Addis Ababa city from April 3 to December 21, 2020. Addis Ababa is the capital city of Ethiopia and the largest city in Ethiopia, with a population of 3,475,952 according to the 2007 population census with an annual growth rate of $2.7 \%$. Addis Ababa has 41 hospitals (13 public and 28 NGO and private). Five federal public hospitals, Tikur Anbesa Specialized Hospital (TASH), St. Paul's hospital (SPHMMC), Addis Ababa Burn, Emergency and Trauma (AaBET) affiliated to St. Paul's hospital, St. Peter hospital and Alert 
hospital were select for this study. The hospitals currently provide ICU care for approximately $1,261,582$ patients per year with 54 ICU beds. ${ }^{22}$

\section{Study Population}

All nurses working in the adult ICU of selected federal public hospitals of Addis Ababa, Ethiopia, during the study period.

\section{Eligibility Criteria}

All adult ICU nurses were included part in the study, while ICU Nurses who were on annual leave were excluded from the study.

\section{Sample Size Determination and Sampling Procedure}

The required sample size for the study was calculated using a single population proportion formula with the assumption of confidence interval $95 \%$, the margin of error $5 \%$, and proportion $51.8 \% \approx 52 \% .{ }^{4}$ Initial sample size $(n i)=(Z a / 2) 2 p(1-p) / d 2=384 ;$ where $Z=$ Standard error of the mean which is corresponding to $95 \%$ confidence level (1.96) were considered. The source populations of the study area were 189 adult ICU nurses who were working in Federal Public Hospitals. Since the total sources of the study population they were less than 10,000, the sample size correction formula was used, $(1+n / N)(1+384 / 189)=127$. Finally, after adding a $10 \%$ nonresponse rate, a total of 140 nurses were targeted for the study.

The number of study participants for each hospital was proportional to the size allocated and those who had been part of the final sample size were selected by using a simple random sampling technique from those found in the adult ICU department during the data collection period.

\section{Data Collection Tools and Procedure}

Pilot tested English version tool developed from up-to-date similar literature, which had contained sociodemographic characteristics, knowledge, utilization of EBP, and barriers for EBP was used to collect data. ${ }^{4,9,10,23,24}$ Data collection was facilitated by five BSc nurses through distributing a structured selfadministered questionnaires.

\section{Data Quality Assurance}

The data quality was assured by daily checking for completeness and consistency throughout the data collection period. Additionally, training was provided for data collectors. The tool was checked for reliability (internal consistency) using the Cronbach's alpha coefficient was 0.77 .

\section{Data Processing and Analysis}

The collected data was checked for its completeness and entered into EPI data version 4.2. Then, it was exported into (SPSS) version 25.0 software to analyze using descriptive statistics and inferential 
statistics. A bivariate and multivariable analysis was done using a binary logistic regression model to see the outcome association between the dependent and independent variables. Those variables with a pvalue of $\leq 0.25$ were transferred to multivariate analysis for identification of independent predictors. The Hosmer and Lemeshow goodness of fit was considered to check model fitness with $p=0.225$. An adjusted odds ratio with $95 \% \mathrm{C}$.I was used to measure the strength of association between dependent and independent variables. P-value $<0.05$ was used to determine the level of statistical significance.

\section{Ethical Consideration}

Ethical clearance was obtained from the Institution Review Board (IRB) of St. Paul hospital Millennium Medical College to carry out the study. A letter of permission was secured from the administrative body of a hospital to communicate with relevant bodies in the health institution. The facilitator was explained the purpose of the study, and then written consent was obtained from the study participants before data collection and confidentiality was maintained at each level of purpose.

\section{Result}

\section{Socio-demographic characteristics of the respondents}

From a total of 135 nurses included in the study, 74 (54.8\%) of them were under the age of 25-29 with a median age of 26 years with an interquartile range (IQR) of 4 years. Among the study participants, 69 $(51.1 \%)$ were females and the rest were male by sex. Concerning the marital status of the study participants, a majority, 79 (58.5\%), were single. The vast majority, $118(87.4 \%)$ of the respondents had BSc degree in nursing, whereas $17(12.6 \%)$ of the nurses had a master's degree in emergency and critical care nursing (EMCCN). The highest proportion of poor knowledge was recorded among those aged between $20-24$ years, which was $41.6 \%(15 / 36)$. Male participants were found to have the highest proportion of good knowledge and utilization in which 78.8\% (52/66), 87.8\% (58/66) were reported to have good knowledge and good utilization of EBP respectively. (Table 1)

\section{Knowledge, utilization of evidence-based practices and factors related with EBP}

Among the study participants, $103(76.3 \%), 87(64.4 \%)$, and $86(63.7 \%)$ of them reported insufficient resources to change practices, severity of critically ill patients and inability to properly interpret the results of research influence were the factors that affect the utilization of EBP respectively. (Table 2)

Furthermore, among those who agreed to have lack of confidence in judging the quality of research $(n=68), 45.6 \%$ (31/68) had poor knowledge of EBP. Again, among those who were confident in judging the quality of research (67), about $21 \%(14 / 67)$ had good utilization of EBP. About $65.2 \%(62 / 95)$ participants among those who responded that nurse managers were supportive had good knowledge of EBP, whereas $75 \%(30 / 40)$ participants among those who disagreed with nurse managers' support had poor knowledge of EBP. Concerning the utilization of EBP, $84.2 \%$ (80/95) of those agreed with having nurse manager's 
support were found to have good utilization, whereas $87.5 \%$ (35/40) of those disagreed with nurse manager's support had good utilization of EBP. (Table 2)

Of the total study subjects, 92(68.1\%) were found to have good knowledge about EBP and the rest 43 (31.9\%) had poor knowledge of EBP. The study findings also revealed that 115 (85\%) of the study subjects had good utilization of EBP. (Table 2)

\section{Factors associated with knowledge of EBP among study participants}

Knowledge of EBP was dichotomized into good and poor knowledge. The, in logistic regression model fitness was checked using Hosmer and Leme show fitness test. In bivariate logistic regression, predictors with $p$ value $<0.25$ were candidates for multivariate logistic regression. In multivariate logistic regression, those predictors having $p$-value $<0.05$ were considered statically significant associations. Variables transferred to multivariate analysis include sex, inability to understand, difficulty in judging, inability to properly, no confident, difficult to understand, EBP has little benefit, nurse managers, nurse colleagues, physicians are supportive, organization, severity of critically ill patient influence, and insufficient resources. (Table 3 )

In multivariate logistic regression, participants who had difficulty to properly interpret research terms were 11.36 times more likely to have poor knowledge compared to their counterparts (AOR=11.36; $95 \% \mathrm{Cl}$ : 1.86-69.39). Similarly, the odds of poor knowledge among ICU nurses who did not receive support from their colleagues were 7 times greater than those who received support from nursing colleagues (AOR=6.96; 95\% Cl: 1.01-47.90). Additionally, nurses who had reported insufficient resources to implement changes in practice were 4.4 times at an increased risk to have poor knowledge of EBP than their counterparts (AOR=4.44; 95\% Cl: 1.05-18.80). (Table 3)

\section{Factors associated with utilization of EBP}

Finally, inability to properly interpret the research, lack of confidence in judging the quality of research, support from nursing colleagues, and having insufficient time were independently associated with the utilization of EBP. The odds of ICU nurses who were not able to interpret the research results were 7.44 times greater than their counterparts (AOR=7.44; 95\% Cl: 1.70-32.56). Likewise, nurses who were confident in judging the quality of research were found to have $76 \%$ more chances for good utilization of $\operatorname{EBP}(A O R=0.24 ; 95 \% \mathrm{Cl}: 0.07-0.83)$. Moreover, ICU nurses who had no support from their colleagues were 6.2 times more likely to have poor utilization of EBP compared to nurses having support from colleagues (AOR=6.176; 95\% Cl: 1.19-32.01). Furthermore, nurses who had insufficient time were revealed to have 4 times more likely to have poor utilization of EBP than their counterparts (AOR=4.05; 95\% Cl: 1.10-14.93).

(Table 4)

\section{Discussion}


The evidence-based practice is thorough and explicit use of current best evidence in making decisions about the care of individual patients, and the integration of best research evidence with clinical expertise and patient practice to predict patient outcomes, improve care quality, and contain costs. ${ }^{1-4}$ Therefore, this study was aimed to determine the level of knowledge and utilization of adult ICU nurses on EBP and its associated factors. About $68.1 \%$ of the participants were found to have good knowledge about EBP, whereas 115 (85.2\%) of them had utilization of EBP. Predictors like inability to properly interpret results, support from nursing colleagues, and insufficient time were found to be independently associated with knowledge of EBP. Predictor variables like lack of confidence in judging research, unable to interpret research results, nursing colleague's support, and insufficient time for practice changes were found to be significantly associated with utilization of EBP.

Our study finding ( $68.1 \%$ of the participants were found to have good knowledge about EBP) was higher than previous studies conducted in Iran ${ }^{20}$, Hunan province, China ${ }^{25}$, Bauchi state, Nigeria ${ }^{26}$, and SNNP, Ethiopia ${ }^{10}$ in which $40 \%, 46 \%, 53.6 \%$ and $54.3 \%$ of the nurses respectively were aware about the concept of EBP. In addition to this, the proportion of good utilization of evidence-based practice among nurses working at intensive care units of adult patients was found to be $85 \%$. Likewise, previous studies conducted in other countries revealed that the utilization of EBP was lower than the current study in which the level of utilization of EBP was reported to be $67.7 \%$ in a study conducted at Australian and New Zealand College of Intensive Care Medicine ${ }^{27}, 57.9 \%$ in Bauchi state, Nigeria ${ }^{26}$ and $53.3 \%$ in the study conducted in Nigeria. ${ }^{28}$ The possible explanation for this discrepancy might be due to several reasons. Firstly, most of the nurses assigned in the ICU were highly experienced. Additionally, in our settings, nurses received short term ICU training and are expected to be frequently exposed to new evidence and practices since they are participating in daily round and bed-side sessions with senior physicians and staff. Moreover, the recent shift in the current curriculum in our country that strengthened and focused on specialty programs such as emergency medicine and critical care training were provided at the BSC and MSc levels. This could contribute to better care provision and increased understanding of EBP applications.

Participants who had difficulty to properly interpret the research results were 11.36 times more likely to have poor knowledge compared to their counterparts. Similarly, the odds of ICU nurses who were not able to interpret the research results were 7.44 times greater than their counterparts. This finding was supported by a former study conducted in South Africa. ${ }^{2}$ This could be justified that nurses who failed to interpret the research findings could face difficulty in applying the findings so that might in turn lead to poor knowledge and utilization of the concept of EBP in their daily activities.

Moreover, ICU nurses who had no support from their colleagues were 6.2 times at an increased risk to have poor utilization of EBP compared to nurses having support from colleagues. This finding is conformable with the findings of studies conducted in Ghana ${ }^{29}$, Nigeria, FETHA II in $2016^{28}$, and Saudi Arabia. ${ }^{25}$ The possible reason could be nurses who lacked support from their colleagues and senior staff were more likely to face difficulties in accessing literature and resources that could enhance the 
understanding of EBP. Senior staff and nurse managers could have more chances to get these resources and the way to get access to related services easily. The other factor that independently associated with the knowledge of ICU nurses on EBP was the insufficiency of time for implementation. Nurses who had insufficient time to implement changes in practice were 4.4 times at an increased risk to have poor knowledge of EBP than their counterparts. This study finding was consistent with studies conducted in Iran, Norway, Saudi Arabia, and Nigeria which revealed that lack of time to practice EBP was associated with knowledge of EBP. ${ }^{3,25,28,30}$ The possible evidence for this could be nurses having insufficient time might face difficulty in searching and reading new evidence and protocols. Furthermore, they would not be able to participate in research projects and innovative ideas. Hence, this could in turn lead to lack of knowledge and understanding of new evidence and practices as well as poor utilization of these protocols. This finally could result in poor utilization of EBP.

\section{Conclusion}

The knowledge and utilization of evidence-based practice (EBP) among nurses working in the adult ICU in this study was found to be high compared to former studies conducted in the area of EBP. Inability to properly interpret research results, lack of confidence in judging the quality of research, insufficient time for implementation of new practices, as well as lack of support from nursing colleagues were factors that were independently associated with poor knowledge and utilization of evidence-based practice among nurses working in adult ICU.

\section{Strength and Limitations of the study}

Since, this study was the first report that was conducted among ICU nurses in which every task is expected to be implemented by protocols. Hence, it will provide more accurate data on evidence-based practice in the field compared to previous studies conducted among nurses working in wards or other departments.

The study might have inaccurate statistical estimations because of the small sample size used in the study, although it was believed to be representative of the source population.

\section{Declarations}

\section{Acknowledgments}

We would like to thank study participants and Saint Paul Hospital Millennium Medical College for technical support during data collection.

\section{Conflicts of interests}

The authors declare no conflicts of interest in this research work. 


\section{Ethics declarations}

\section{Ethics approval and consent to participate}

Ethical clearance was obtained from the Institution Review Board (IRB) of St. Paul hospital Millennium Medical College to carry out the study. A letter of permission was secured from the administrative body of a hospital to communicate with relevant bodies in the health institution. The facilitator was explained the purpose of the study, and then written consent was obtained from the study participants before data collection and confidentiality was maintained at each level of purpose.

\section{Consent for publication}

Not applicable.

\section{Availability of data and materials}

The datasets generated and analyzed during the current study are not publicly available due to these data were used under license for the current study but are available from the corresponding author on reasonable request.

\section{Funding}

This study was funded by Saint Paul Hospital Millennium Medical College. Other than funding, this institution had not taken part in the design of the study and collection, analysis, interpretation of data, and writing of this manuscript.

\section{Authors' contributions}

The first two authors (Zerihune Alene,Negat W/Hawariat) wrote the introduction literature and review methods and material part, Helina Bogale was did the analysis part,Ayele Fikadu wrote the discussion section and Abdata Workina wrote the conclusion part of the manuscript. Finally all authors participated to finalize and review the manuscript.

\section{References}

1. Sánchez-García I, Ureña Molina M del P, López-Medina IM, Pancorbo-Hidalgo PL. Knowledge, skills and attitudes related to evidence-based practice among undergraduate nursing students: A survey at three universities in Colombia, Chile and Spain. Nurse Educ Pract. 2019;39(August):117-123. doi:10.1016/j.nepr.2019.08.009

2. Jordan $P$, Bowers $C$, Morton D. Barriers to implementing evidence-based practice in a private intensive care unit in the Eastern Cape. South Afr J Crit Care. 2016;32(2):50-54.

doi:10.7196/SAJCC.2016.v32i2.253 
3. Stokke K, Olsen NR, Espehaug B, Nortvedt MW. Evidence based practice beliefs and implementation among nurses: A cross-sectional study. BMC Nurs. 2014;13(1). doi:10.1186/1472-6955-13-8

4. Dawit $H$, Abinet $A$, Terefe $M$. Evidence based nursing practice and associated factors among nurses working in Jimma zone public hospitals, Southwest Ethiopia. Int J Nurs Midwifery. 2018;10(5):47-53. doi:10.5897/ijnm2017.0294

5. John SM, Jennings-Sanders A. Assessing Knowledge of Evidence-Based Practice among Nurses. ProQuest Diss Theses. Published online 2016:85.

6. Zhao J. Evidence - based nursing outputs and hot spot analysis of the last 5 years in mainland China: Results of a bibliometric analysis. 2018;(May 2017):1-9. doi:10.1111/ijn.12628

7. Kyalo MA, Elmer J, Kahn JM, et al. Guest Editorial Guest Editorial. Nurs Pract. 2015;6(1):73. doi:10.1186/1472-6955-13-8

8. Chiwaula $\mathrm{CH}$, Chinkhata $\mathrm{M}$, Kamera $\mathrm{H}$, Haruzivishe C. Evidence Based Practice: A Concept Analysis. Health Syst Policy Res. 2018;05(03):1-7. doi:10.21767/2254-9137.100094

9. Hadgu G. Assessment of Nurses' Perceptions and Barriers on Evidence Based Practice in Tikur Anbessa Specialized Hospital Addis Ababa Ethiopia. Am J Nurs Sci. 2015;4(3):73. doi:10.11648/j.ajns.20150403.15

10. Tadesse B, Teshome H, Eyoel A. Assessment of Nurses Knowledge and Utilization of Evidence based Practice and its Associated Factors in Selected Hospitals of Southern Advanced Practices in Nursing. 2018;3(2):6-12. doi:10.4172/2573-0347.1000150

11. Bostro A, Kiessling A. Capability beliefs on , and use of evidence- based practice among four health professional and student groups in geriatric care: A cross sectional study. Published online 2018:115.

12. Melnyk BM, Pmhnp C. The State of Evidence-Based Practice in US Nurses Critical Implications for Nurse Leaders and Educators. 2012;42(9):410-417. doi:10.1097/NNA.0b013e3182664e0a

13. Zeb A. Barriers to Evidence Based Nursing Practice in Tertiary Care Hospitals of Peshawar, Pakistan. Biomed J Sci Tech Res. 2018;8(1). doi:10.26717/bjstr.2018.08.001592

14. Zhou F, Hao Y, Guo H, Liu H. Attitude, Knowledge, and Practice on Evidence-Based Nursing among Registered Nurses in Traditional Chinese Medicine Hospitals: A Multiple Center Cross-Sectional Survey in China. 2016;2016.

15. Majid S, Foo S, Zhang X, et al. Nurses' information use and literature searching skills for evidence based practices. Malays J Libr Inf Sci. 2013;18(1):67-78.

16. Esfandani K, Aliyari S, Pishgooei AH, Ebadi A. Promoting Critical Care Nurses ' Information Literacy Through an Evidence- Based Practice Workshop: A Quasi-Experimental Study Promoting Critical Care Nurses ' Information Literacy Through an Evidence-Based Practice Workshop: A Quasi-Experimental Study. 2017;(May). doi:10.5812/ccn.12042

17. Brysiewicz P. Intensive care nursing in South Africa Intensive care nursing in South Africa. 2015;(July 2011). 
18. Borgert M, Binnekade J, Paulus F, Goossens A, Dongelmans D. A flowchart for building evidencebased care bundles in intensive care: Based on a systematic review. Int $J$ Qual Health Care. 2017;29(2):163-175. doi:10.1093/intqhc/mzx009

19. Organization WH. WHO Europe Critical Care Nursing Curriculum. Published online 2003:1-42.

20. Farokhzadian J, Khajouei R, Ahmadian L. Evaluating factors associated with implementing evidencebased practice in nursing. J Eval Clin Pract. 2015;21(6):1107-1113. doi:10.1111/jep.12480

21. Beyea S, Slattery M. Evidence-based practice in nursing - A guide to successful implementation. HCPro Inc. Published online 2006:1-18.

22. Ketema AH, Berhe AT, Advisor P, et al. Addis Ababa, Ethiopia Enhancing Urban Resilience ETHIOPIAN FEDERAL GOVERNMENT Borja Santos Porras Wondwossen Regassa CITY OF ADDIS ABABA Ato Fikre Tekeste Deputy Head, Addis Ababa Water and Sewerage Authority. 2015;(July).

23. Dereje B, Hailu E, Beharu M. Evidence-based Practice Utilization and Associated Factors among Nurses Working in Public Hospitals of Jimma Zone Southwest Ethiopia: A Cross Sectional Study. Gen Med Open Access. 2019;07(01):1-10. doi:10.35248/2327-5146.7.321

24. Black AT, Balneaves LG. Promoting Evidence-Based Practice Through a Research Training Program for Point-of-Care Clinicians. 2015;45(1):14-20. doi:10.1097/NNA.0000000000000151

25. Alatawi M, Aljuhani E, Alsufiany F, et al. Barriers of Implementing Evidence-Based Practice in Nursing Profession: A Literature Review. 2020;9(1):35-42. doi:10.11648/j.ajns.20200901.16

26. Aliyu AS, Umar NY, Adamu A, Bura HA. Epidemiological Assessment of Nurses ' Knowledge and Utilization of Evidence Based Practice and its Associated Factors in Specialist Hospital Bauchi State , Nigeria. 2020;5(3):31-38.

27. Heighes PT, Doig GS. Intensive care specialists ' knowledge, attitudes, and professional use of published research evidence: A mail-out questionnaire survey of appropriate use of research evidence in clinical practice $\otimes$. J Crit Care. 2014;29(1):116-122. doi:10.1016/j.jcrc.2013.10.014

28. Ahaiwe VC, Ezeruigbo Chinwe Florence Samantha, Emeh Augusta Nkechi. Evaluation of barriers to the implementation of evidence- based practice (EBP) among nurses working at federal teaching hospital Abakaliki (FETHA II). Int J Nurs Midwife Health Relat Cases. 2016;Vol.2, No.(1):71-90.

29. Access O. research in three hospitals within the Kumasi Metropolis, Ghana. 2018;8688:1-11. doi:10.11604/pamj.2018.30.24.15230

30. Khammarnia M, Haj Mohammadi M, Amani Z, Rezaeian S, Setoodehzadeh F. Barriers to Implementation of Evidence Based Practice in Zahedan Teaching Hospitals, Iran, 2014. Nurs Res Pract. 2015;2015:1-5. doi:10.1155/2015/357140

\section{Tables}

Table 1: Distribution of socio-demographic characteristics among nurses who had been working in adult ICU of federal public hospitals, Addis Ababa, Ethiopia, $2020(n=135)$ 


\begin{tabular}{|c|c|c|c|c|c|c|}
\hline \multirow[t]{3}{*}{ Independent variables } & \multirow{3}{*}{ Category } & \multicolumn{5}{|c|}{ Outcome variable } \\
\hline & & \multicolumn{2}{|c|}{ Knowledge } & \multicolumn{2}{|c|}{ Utilization } & \multirow[b]{2}{*}{ Total n (\%) } \\
\hline & & Good & Poor & Good & Poor & \\
\hline \multirow[t]{3}{*}{ Age Group } & $15-34$ & 84 & 41 & 107 & 18 & $1(92.6)$ \\
\hline & $\geq 35$ & 8 & 2 & 8 & 2 & $10(7.3)$ \\
\hline & Total & 92 & 43 & 115 & 20 & 135 (100\%) \\
\hline \multirow[t]{3}{*}{ Sex } & Male & 52 & 14 & 58 & 8 & $66(48.9)$ \\
\hline & Female & 40 & 29 & 57 & 12 & $69(51.1)$ \\
\hline & Total & 92 & 43 & 115 & 20 & $135(100)$ \\
\hline \multirow[t]{4}{*}{ Marital Status } & Single & 58 & 21 & 68 & 11 & $79(58.5)$ \\
\hline & Married & 32 & 20 & 43 & 9 & $52(38.5)$ \\
\hline & Others* & 2 & 2 & 4 & 0 & $4(2.9)$ \\
\hline & Total & 92 & 43 & 115 & 20 & $135(100)$ \\
\hline \multirow[t]{7}{*}{ Experience in Year } & $1-3$ & 38 & 21 & 50 & 9 & $59(43.7)$ \\
\hline & $4-6$ & 38 & 15 & 44 & 9 & $53(39.3)$ \\
\hline & $7-9$ & 9 & 3 & 10 & 2 & $12(8.9)$ \\
\hline & $10-12$ & 6 & 3 & 9 & 0 & $9(6.7)$ \\
\hline & $13-15$ & 0 & 1 & 1 & 0 & $1(.7)$ \\
\hline & $16-18$ & 1 & 0 & 1 & 0 & $1(.4)$ \\
\hline & Total & 92 & 43 & 115 & 20 & $135(100)$ \\
\hline \multirow[t]{6}{*}{ Work Position } & Staff Nurse & 76 & 36 & 94 & 18 & $112(83.0)$ \\
\hline & ECCN & 11 & 5 & 15 & 1 & $16(11.9)$ \\
\hline & EMCCN & 0 & 1 & 1 & 0 & $1(.7)$ \\
\hline & Public health & 1 & 0 & 1 & 0 & $1(.7)$ \\
\hline & Head Nurse & 4 & 1 & 4 & 1 & $5(3.7)$ \\
\hline & Total & 92 & 43 & 115 & 20 & $135(100)$ \\
\hline \multirow[t]{3}{*}{ Educational Level } & BSc & 81 & 37 & 100 & 18 & $118(87.4)$ \\
\hline & MSc & 11 & 6 & 15 & 2 & $17(12.6)$ \\
\hline & Total & 92 & 43 & 115 & 20 & $135(100)$ \\
\hline
\end{tabular}


Note: * Divorced, Widowed

Table 2: Knowledge, utilization of evidence-based practices and factors related to EBP among adult ICU nurses who had been working in federal public hospitals, Addis Ababa, Ethiopia, $2020(n=135)$ 


\begin{tabular}{|c|c|c|c|c|c|c|c|}
\hline \multirow[t]{2}{*}{ Covariates } & \multirow[t]{2}{*}{ Category } & \multicolumn{2}{|c|}{ Knowledge } & \multirow[t]{2}{*}{ Total } & \multicolumn{2}{|c|}{ Utilization } & \multirow[t]{2}{*}{ Tota } \\
\hline & & Good & Poor & & Good & Poor & \\
\hline \multirow[t]{3}{*}{ Lack of autonomy to change practice } & Yes & 65 & 33 & 98 & 84 & 14 & 98 \\
\hline & No & 27 & 10 & 37 & 31 & 6 & 37 \\
\hline & Total & 92 & 43 & 135 & 115 & 20 & 135 \\
\hline \multirow{3}{*}{$\begin{array}{l}\text { Inadequate understanding of research } \\
\text { terms }\end{array}$} & Yes & 52 & 28 & 80 & 67 & 13 & 80 \\
\hline & No & 40 & 15 & 55 & 48 & 7 & 55 \\
\hline & Total & 92 & 43 & 135 & 115 & 20 & 135 \\
\hline \multirow{3}{*}{$\begin{array}{l}\text { Inability to properly interpret the result } \\
\text { of research }\end{array}$} & Yes & 53 & 33 & 86 & 69 & 17 & 86 \\
\hline & No & 39 & 10 & 49 & 46 & 3 & 49 \\
\hline & Total & 92 & 43 & 135 & 115 & 20 & 135 \\
\hline \multirow{3}{*}{$\begin{array}{l}\text { No confidence in judging quality of } \\
\text { research }\end{array}$} & Yes & 37 & 31 & 68 & 62 & 6 & 68 \\
\hline & No & 55 & 12 & 67 & 53 & 14 & 67 \\
\hline & Total & 92 & 43 & 135 & 115 & 20 & 135 \\
\hline \multirow[t]{3}{*}{ EBP has little benefit for nurses } & Yes & 31 & 23 & 54 & 49 & 5 & 54 \\
\hline & No & 61 & 23 & 84 & 66 & 15 & 81 \\
\hline & Total & 92 & 46 & 135 & 115 & 20 & 135 \\
\hline \multirow{3}{*}{$\begin{array}{l}\text { Nurse managers are supportive to } \\
\text { implement EBP }\end{array}$} & Yes & 62 & 33 & 95 & 80 & 15 & 95 \\
\hline & No & 30 & 10 & 40 & 35 & 5 & 40 \\
\hline & Total & 92 & 43 & 135 & 115 & 20 & 135 \\
\hline \multirow{3}{*}{$\begin{array}{l}\text { Physicians are supportive to } \\
\text { implement EBP }\end{array}$} & Yes & 61 & 32 & 93 & 82 & 11 & 93 \\
\hline & No & 31 & 11 & 42 & 33 & 9 & 42 \\
\hline & Total & 92 & 43 & 135 & 115 & 20 & 135 \\
\hline \multirow{3}{*}{$\begin{array}{l}\text { Lack of authority in in critical care unit } \\
\text { to change }\end{array}$} & Yes & 68 & 32 & 100 & 86 & 14 & 100 \\
\hline & No & 24 & 11 & 35 & 29 & 6 & 35 \\
\hline & Total & 92 & 43 & 135 & 115 & 20 & 135 \\
\hline \multirow{3}{*}{$\begin{array}{l}\text { The severity of critically ill patient } \\
\text { influence }\end{array}$} & Yes & 53 & 34 & 87 & 73 & 14 & 87 \\
\hline & No & 39 & 9 & 48 & 42 & 6 & 48 \\
\hline & Total & 92 & 43 & 135 & 115 & 20 & 135 \\
\hline
\end{tabular}




\begin{tabular}{|llllllll|}
$\begin{array}{l}\text { Insufficient resources to change } \\
\text { practices }\end{array}$ & Yes & 69 & 34 & 103 & 88 & 15 & 103 \\
\cline { 2 - 7 } & No & 23 & 9 & 32 & 27 & 5 & 32 \\
\cline { 2 - 6 } & Total & 92 & 43 & 135 & 115 & 20 & 135 \\
\hline Knowledge of EBP & Good & $92(68.1 \%)$ & & & & \\
Utilization of EBP & Poor & $43(31.9 \%)$ & & & \\
& Good & $115(85.2 \%)$ & & & \\
& Poor & $20(14.8 \%)$ \\
\hline
\end{tabular}

Table 3: Bivariate and multivariate logistic regression analysis for adult ICU nurse's knowledge on EBP who had been working in federal public hospitals, Addis Ababa, Ethiopia, $2020(n=135)$. 


\begin{tabular}{|c|c|c|c|c|c|c|c|}
\hline \multirow[t]{2}{*}{ Covariate } & \multirow[t]{2}{*}{ Category } & \multicolumn{2}{|c|}{ Knowledge } & \multirow{2}{*}{$\begin{array}{l}\text { p- } \\
\text { value }\end{array}$} & \multirow{2}{*}{$\begin{array}{l}\text { COR } \\
(95 \% \mathrm{Cl})\end{array}$} & \multirow{2}{*}{$\begin{array}{l}\text { p- } \\
\text { value }\end{array}$} & \multirow{2}{*}{$\begin{array}{l}\text { AOR } \\
\text { (95\% } \\
\text { Cl) }\end{array}$} \\
\hline & & Good & Poor & & & & \\
\hline \multirow[t]{2}{*}{ Sex } & Male & 52 & 14 & 0.011 & $\begin{array}{l}2.693 \\
(1.26- \\
5.76)\end{array}$ & 0.757 & $\begin{array}{l}0.83 \\
(0.25- \\
2.72)\end{array}$ \\
\hline & Female & 40 & 29 & 1 & 1 & 1 & 1 \\
\hline \multirow[t]{2}{*}{ Inability to understand } & Yes & 49 & 31 & 0.040 & $\begin{array}{l}2.267 \\
(1.04- \\
4.96)\end{array}$ & 0.710 & $\begin{array}{l}0.76 \\
(0.18- \\
3.27)\end{array}$ \\
\hline & No & 43 & 12 & 1 & 1 & 1 & 1 \\
\hline \multirow[t]{2}{*}{ Difficulty in judging } & Yes & 54 & 36 & 0.006 & $\begin{array}{l}3.62 \\
(1.46- \\
8.99)\end{array}$ & 0.655 & $\begin{array}{l}0.70 \\
(0.15- \\
3.28)\end{array}$ \\
\hline & No & 38 & 7 & 1 & 1 & 1 & 1 \\
\hline \multirow[t]{2}{*}{ Inability to properly } & Yes & 53 & 33 & 0.034 & $\begin{array}{l}2.43 \\
(1.07- \\
5.51)\end{array}$ & 0.008 & $\begin{array}{l}11.36 \\
(1.86- \\
69.39) \\
*\end{array}$ \\
\hline & No & 39 & 10 & 1 & 1 & 1 & 1 \\
\hline \multirow[t]{2}{*}{ No confidence } & Yes & 37 & 31 & 0.001 & $\begin{array}{l}3.84 \\
(1.75- \\
8.43)\end{array}$ & 0.052 & $\begin{array}{l}0.27 \\
(0.07- \\
1.01)\end{array}$ \\
\hline & No & 55 & 12 & 1 & 1 & 1 & 1 \\
\hline \multirow[t]{2}{*}{ Difficult to understand } & Yes & 32 & 23 & 0.041 & $\begin{array}{l}2.16 \\
(1.03- \\
4.51)\end{array}$ & 0.476 & $\begin{array}{l}0.574 \\
(.124- \\
2.64)\end{array}$ \\
\hline & No & 60 & 20 & 1 & 1 & 1 & 1 \\
\hline \multirow[t]{2}{*}{ EBP has little benefit } & Yes & 31 & 23 & 0.030 & $\begin{array}{l}2.26 \\
(1.08- \\
4.74)\end{array}$ & 0.147 & $\begin{array}{l}0.365 \\
(094- \\
1.43)\end{array}$ \\
\hline & No & 61 & 20 & 1 & 1 & 1 & 1 \\
\hline \multirow[t]{2}{*}{ Nurse managers } & Yes & 62 & 33 & 0.247 & $\begin{array}{l}1.60 \\
(0.70- \\
3.67)\end{array}$ & 0.846 & $\begin{array}{l}0.862 \\
(0.19- \\
3.89)\end{array}$ \\
\hline & No & 30 & 10 & 1 & 1 & 1 & 1 \\
\hline \multirow[t]{2}{*}{ Nursing colleagues } & Yes & 72 & 28 & 1 & 1 & 1 & 1 \\
\hline & No & 20 & 15 & 0.107 & $\begin{array}{l}0.52 \\
(0.23- \\
1.153)\end{array}$ & 0.049 & $\begin{array}{l}6.96 \\
(1.01-\end{array}$ \\
\hline
\end{tabular}




\begin{tabular}{|c|c|c|c|c|c|c|c|}
\hline & & & & & & & $\begin{array}{l}47.90) \\
*\end{array}$ \\
\hline \multirow[t]{2}{*}{ Physician's support } & Yes & 61 & 32 & 0.244 & $\begin{array}{l}1.48 \\
(0.66- \\
3.32)\end{array}$ & 0.076 & $\begin{array}{l}0.23 \\
(0.05- \\
1.17)\end{array}$ \\
\hline & No & 31 & 11 & 1 & 1 & 1 & 1 \\
\hline \multirow[t]{2}{*}{ The organization } & Yes & 72 & 29 & 0.180 & $\begin{array}{l}0.58 \\
(0.26- \\
1.2)\end{array}$ & 0.179 & $\begin{array}{l}3.22 \\
(0.59- \\
17.64)\end{array}$ \\
\hline & No & 20 & 14 & 1 & 1 & 1 & 1 \\
\hline \multirow[t]{2}{*}{ Insufficient resources } & Yes & 47 & 33 & 0.006 & $\begin{array}{l}3.16 \\
(1.40- \\
7.15)\end{array}$ & 0.043 & $\begin{array}{l}4.438 \\
(1.05- \\
18.8) \text { * }\end{array}$ \\
\hline & No & 45 & 10 & 1 & 1 & 1 & 1 \\
\hline \multirow[t]{2}{*}{$\begin{array}{l}\text { Severity of critically ill } \\
\text { patient influence }\end{array}$} & Yes & 53 & 34 & 0.017 & $\begin{array}{l}2.78 \\
(1.20- \\
6.46)\end{array}$ & 0.633 & $\begin{array}{l}1.416 \\
(0.34- \\
5.90)\end{array}$ \\
\hline & No & 39 & 9 & 1 & 1 & 1 & 1 \\
\hline
\end{tabular}

Table 4: Binary and multivariate logistic regression analysis for adult ICU nurse's utilization on EBP who had been working in federal public hospitals, Addis Ababa, Ethiopia, 2020 ( $n=135)$. 


\begin{tabular}{|c|c|c|c|c|c|c|c|}
\hline \multirow[t]{2}{*}{ Covariate } & \multirow[t]{2}{*}{ Category } & \multicolumn{2}{|c|}{ Utilization } & \multirow{2}{*}{$\begin{array}{l}\text { p- } \\
\text { value }\end{array}$} & \multirow{2}{*}{$\begin{array}{l}\mathrm{COR}(95 \% \\
\mathrm{Cl})\end{array}$} & \multirow{2}{*}{$\begin{array}{l}\mathrm{P} \text { - } \\
\text { value }\end{array}$} & \multirow{2}{*}{$\begin{array}{l}\text { AOR }(95 \% \\
\text { Cl) }\end{array}$} \\
\hline & & Good & Poor & & & & \\
\hline \multirow[t]{2}{*}{$\begin{array}{l}\text { Inability to properly } \\
\text { interpret research }\end{array}$} & Yes & 69 & 17 & 0.042 & $\begin{array}{l}3.78(1.05- \\
13.63)\end{array}$ & 0.008 & $\begin{array}{l}7.44(1.70- \\
32.56) *\end{array}$ \\
\hline & No & 46 & 3 & & 1 & 1 & 1 \\
\hline \multirow[t]{2}{*}{ No confident to judge } & Yes & 62 & 6 & 1 & 1 & 1 & 1 \\
\hline & No & 53 & 14 & 0.055 & $\begin{array}{l}0.37 \\
(0.13- \\
1.02)\end{array}$ & 0.024 & $\begin{array}{l}0.24(0.07- \\
0.83) \star\end{array}$ \\
\hline \multirow[t]{2}{*}{ EBP has little benefit } & Yes & 49 & 5 & 0.145 & $\begin{array}{l}0.45 \\
(0.15- \\
1.32)\end{array}$ & 0.192 & $\begin{array}{l}0.43(0.12- \\
1.53)\end{array}$ \\
\hline & No & 66 & 15 & 1 & 1 & 1 & 1 \\
\hline \multirow[t]{2}{*}{ Nursing colleagues } & Yes & 83 & 17 & 1 & 1 & 1 & 1 \\
\hline & No & 32 & 3 & 0.236 & $\begin{array}{l}2.19 \\
(0.60- \\
7.96)\end{array}$ & 0.030 & $\begin{array}{l}6.176(1.19- \\
32.01) *\end{array}$ \\
\hline \multirow[t]{2}{*}{$\begin{array}{l}\text { Physicians are } \\
\text { supportive }\end{array}$} & Yes & 82 & 11 & 0.151 & $\begin{array}{l}0.49 \\
(0.19- \\
1.30)\end{array}$ & 0.131 & $\begin{array}{l}0.387 \\
(0.11-1.33)\end{array}$ \\
\hline & No & 33 & 9 & & 1 & 1 & 1 \\
\hline \multirow[t]{2}{*}{ Insufficient time } & Yes & 66 & 14 & 0.249 & $\begin{array}{l}1.73 \\
(0.62- \\
4.83)\end{array}$ & 0.036 & $\begin{array}{l}4.05(1.10- \\
14.93) \text { * }\end{array}$ \\
\hline & No & 49 & 6 & & 1 & 1 & 1 \\
\hline
\end{tabular}

